\title{
Os pontos de virada na formação do professor universitário: um estudo sobre o mecanismo da identificação
}

Claudia Rosa Riolfi

Cláudia Alaminos

Universidade de São Paulo

\begin{abstract}
Resumo
0 presente artigo tem como objeto a formação do professor universitário. Volta-se para a elucidação das seguintes questões: a) os avanços para a compreensão da natureza do percurso a ser trilhado para que se instale, no professor universitário em formação, um desejo que encontre seu norte no ato de ensinar que são possiveis de se levar em consideração, ao tomar em consideração a psicanálise lacaniana; e b) a configuração dos pontos de virada por meio dos quais um sujeito em formação vem a construir um lugar singular de onde possa criar um trabalho próprio de professor universitário. Postula a necessidade do ultrapassamento do que estamos chamando de pontos de virada para que aquele que está em um percurso de formação, para se tornar professor universitário, possa vir a criar um espaço próprio para o exercício da docência, fundando, portanto, a possibilidade da re-invenção de um si próprio. Para tal fim, estamos recorrendo ao conceito de identificação - tal qual é visto na psicanálise de orientação lacaniana - para elucidar a experiência decorrida no âmbito do Programa de Aperfeiçoamento de Ensino (PAE), ao longo de 2005, em duas disciplinas (cujos alunos são prioritariamente oriundos da graduação em lingüística da Faculdade de Filosofia, Letras e Ciências Humanas da USP), que têm a carga horária de 120 horas cada uma (60 em sala de aula e 60 de estágio supervisionado).
\end{abstract}

\section{Palavras-chave}

Formação do professor universitário - Singularidade - Identificação. 


\title{
The "turning points" in the formation of the university teacher: a study of the mechanism of identification
}

\author{
Claudia Rosa Riolfi \\ Cláudia Alaminos \\ University of São Paulo
}

\begin{abstract}
This article takes as its object the formation of the university teacher, turning its attention to the elucidation of the following issues: a) the developments in the understanding of the nature of the path to be followed so as to instill in the university teacher under formation a will oriented towards the act of teaching, developments that can be assessed from the perspective of Lacanian psychoanalysis; and b) the configuration of "turning points" after which a subject under formation builds a singular place where it is possible to develop a work proper to an university teacher. The text postulates the need to go beyond what we have been calling "turning points", so as to allow those walking the path of formation to become university teachers to create a space conducive to the exercise of teaching, thereby instating the possibility of re-inventing themselves. To such end, we make use of the concept of "identification" - such as seen in Lacanian psychoanalysis - to elucidate the experience acquired during 2005 with the Teaching Improvement Program (PAE) in two disciplines (whose students come chiefly from the undergraduate course in Linguistics of the Faculty of Philosophy, Letters and Human Sciences of USP) with a total dedication of 120 hours each (60 hours of classes and 60 hours of supervised work).
\end{abstract}

\section{Keywords}

University teacher education - Singularity - Identification.

Contact:

Claudia Rosa Riolfi

Av. Nossa $S^{\text {ra }}$ da Assunção, 675 ap $12 E$

05359-001 - São Paulo - SP

e-mail: riolfi@usp.br 
On n'est pas responsable que dans la mesure de son savoir-faire.

Qu'est-ce que c'est le savoir-faire ? C'est l'art, l'artifice, ce qui donne à l'art dont on est capable une valeur remarquable, parce qui'il n'y a pas d'Autre de l'Autre pour opérer le Jugement dernier.' (Lacan, 1975-76, p. 61)

Tendo como ponto de partida uma preocupação com a formação do professor universitário que visa trabalhar com as disciplinas ligadas à linguagem humana, o presente trabalho voltase para a elucidação das seguintes questões:

a) quais avanços são possíveis de se levar em consideração, ao tomar em consideração a psicanálise lacaniana, para a compreensão da natureza do percurso a ser trilhado para que se instale, no professor universitário em formação, um desejo que encontre seu norte no ato de ensinar?; e

b) quais são os pontos de virada por meio dos quais um sujeito em formação - ocupando inicialmente o lugar genérico de aluno vem a construir um lugar singular de onde possa criar um trabalho próprio de professor universitário?

Já disse algum poeta que, antes de nascer, todas as coisas tiveram origem no mundo dos sonhos. Deixando em suspenso a veracidade do qualificador todas, cumpre dizer que tal é o caso do presente trabalho, cujo advento ocorreu bem antes de sua efetiva concretização. Para estabelecer um marco que fixe seu início, diremos que sua origem remonta ao 1 Seminário de Ensino e Produção no Ensino Superior, realizado no Congresso de Leitura - COLE, em julho de 1999.

A escolha de tal evento para fixar nossa pedra angular deve-se ao fato de que, na conferência de abertura desse Seminário, julgou-se importante explicitar a opção ética que nos levou a fundar esse espaço de discussão para congregar professores universitários e, para tal fim, forjar a palavra formacriação para nomear o drama que todo professor em formação deve superar.
Esclareça-se que, por meio dessa palavra, visava-se dar a ver a hipótese segundo a qual, para que qualquer possibilidade de criação vigore em um percurso de formação do professor, há de se superar a conseqüência mesma desse processo: a tendência que a geração que está sendo formada tem de reproduzir, em suas glórias e em seus sintomas, os principais traços da geração precedente. Advogávamos na direção de que a introdução sistemática e deliberada da dimensão da criação na formação do professor era urgente para que fôssemos além de enquadrar o novato no discurso da geração precedente, durante o ato de formá-lo (Riolfi, 2001).

Um segundo momento importante, para a fundação do presente texto, se deu por ocasião da escrita de um trabalho que explorava os desdobramentos de uma cena de sala de aula, durante a qual a seguinte frase foi dita pelos alunos à sua professora de Língua Portuguesa, após terem tomado a iniciativa de surpreendêla com a realização de uma brincadeira chamada tchu tchu: "Professora, a senhora já imaginou que escândalo seria fazer tchu tchu com uma professora aqui da Federal?" (Riolfi, 2002).

A análise desse enunciado e de suas condições de produção mostrou que seus locutores apresentaram sua condição de divisão. Se, por um lado, reconheciam o pertencimento de seu interlocutor à classe das senhoras professoras da Federal, por outro, podiam levar em conta sua diferença com relação a todas as outras professoras. Tomando emprestados aqui dois termos de uso comum na filosofia, podemos dizer que, ao ousar fazer o jogo e, mais tarde, ao reconhecer seu caráter escandaloso, a singularidade da professora foi levada em conta na relação pedagógica.

Por esse motivo, puderam vivenciá-la em um regime de exceção (tomando-se como parâmetro o modo como as relações pedagógicas

1."Torna-se responsável unicamente na medida de seu saber-fazer. 0 que é 0 saber-fazer? É a arte, 0 artifício, 0 que dá à arte que alguém consegue concretizar um valor único, porque não há um Outro do Outro para operar um julgamento inquestionável." (A tradução é nossa) 
costumam se dar em nível universitário). Puderam aprender seriamente sem deixar de brincar livremente. Naquele trabalho, mostrou-se ainda que a operação de ressignificação do significante professora adveio do deslocamento do lugar que é dado ao professor por seus alunos. A tese defendida na ocasião refere-se ao fato de que, em uma relação pedagógica produtiva, em um primeiro tempo, o professor se presta a ser uma superfície especular na qual o aluno pode se projetar de forma idealizada, dizendo: quando eu crescer, eu quero ser igual a ele.

Nesse momento da reflexão, três anos após a publicação daquele trabalho, interessanos complementá-lo, dialetizando-o. Tomando, a título de estudo de caso, uma experiência ocorrida no Programa de Pós-Graduação da Faculdade de Educação da Universidade de São Paulo - FEUSP -, vamos tematizar a formação do professor universitário analisando dois semestres de trabalho de uma docente e de uma estagiária - que nunca teve experiência prévia lecionando no Ensino Superior - no âmbito do Estágio Supervisionado em Docência previsto no Programa de Aperfeiçoamento de Ensino - $P A E^{2}$.

\section{Tornando-se professor universitário no âmbito do PAE}

Para uma melhor compreensão da experiência que aqui será nosso objeto de análise, parece-nos necessário discorrer sobre o programa no qual o estágio se deu. Por esse motivo, passaremos a expor o regimento e as características do PAE para, posteriormente, nos ocuparmos do caso em questão.

0 PAE destina-se aos alunos de Pós-Graduação matriculados nos cursos de mestrado e doutorado da Universidade de São Paulo, sendo de caráter opcional. Ele é de caráter obrigatório àqueles que são contemplados pela Bolsa Demanda Social da Coordenação de Aperfeiçoamento de Pessoal de Nível Superior - CAPES -, cujo regulamento exige a realização de estágio ${ }^{3}$.

Na regulamentação do estágio, está claro que ele se trata exclusivamente de estágio de docência, compreendido como parte integrante da formação do pós-graduando que, de acordo com a política adotada pela CAPES em direção à qualificação do ensino de graduação, deve ser preparado para a docência.

É necessário esclarecer que o programa PAE foi criado em 1992, tendo assumido suas caracteristicas atuais em 1994. A regulamentação do programa se deu em 2002 (Portaria GR 3347) a qual recebeu duas modificações: em 2003 (Portaria GR 3423) e em 2005 (Portaria GR 3588). Conforme consta na Portaria GR 3588, seu objetivo é "aprimorar a formação do pós-graduando para atividade didática de graduação" (Universidade de São Paulo, 2005).

Oito anos após a sua criação, foram realizados dois eventos na USP com o objetivo de refletir sobre o programa e gerar propostas para o seu aperfeiçoamento ${ }^{4}$. A partir do segundo, a Pró-Reitoria de Pós-Graduação estabeleceu uma publicação denominada PAE: Programa de Aperfeiçoamento de Ensino, a qual informa que a preocupação com a formação dos alunos da pós-graduação para a docência de terceiro grau existia nas diferentes unidades da USP bem antes que a CAPES tornasse o PAE obrigatório para todas as instituições integrantes do Programa de Demanda Social.

Ainda de acordo com o site da USP, a composição do PAE consiste em duas etapas: Preparação Pedagógica ${ }^{5}$ e Estágio Supervisionado em Docência. A Etapa de Preparação Pedagógica tem como objetivo refletir sobre as questões do Ensino Superior e instrumentalizar o aluno para o exercício da função docente. De

2. Deve-se ressaltar que o estágio de docência tem a nomenclatura Programa de Aperfeiçoamento de Ensino (PAE) na USP, Programa de Estágio Docente (PED) na Universidade Estadual de Campinas (UNICAMP) e Estágio de Docência na Universidade Estadual Paulista (UNESP), do que se pode concluir que cada universidade dá ao estágio a sua nomenclatura. De acordo com Pimenta e Anastasiou (2001), as iniciativas operacionalizadas pelo PAE estão em consonância com programas similares desenvolvidos em grandes universidades de diferentes países.

3. Regulamentado pela Portaria CAPES n. 52 de 2002.

4. A saber, a I Jornada sobre o PAE e o estágio CAPES (em 2000) e 0 Workshop do PAE (em 2001).

5. Nessa publicação, consta ainda uma outra informação relevante: a de que a Etapa de Preparação Pedagógica para os participantes do PAE foi instituída em 1999 (Universidade de São Paulo, 2001). 
acordo com as normas da USP, ela pode ser cumprida pela participação em: a) uma disciplina de Pós-Graduação $0^{6}$; b) um conjunto de conferências com especialistas da área de Educação; e c) pela participação em um núcleo de atividades que envolve preparo de material didático, discussões de curriculum, de ementas de disciplinas e planejamento de cursos.

Por sua vez, a Etapa de Estágio Supervisionado em Docência é realizada em disciplinas de graduação, devendo o interessado se inscrever na Unidade de Ensino da área de conhecimento pertinente ao seu curso, mediante a apresentação de um plano de trabalho no qual deverão constar as atividades que serão desenvolvidas numa disciplina específica, sob a supervisão do professor responsável.

Para concluir essa exposição, podemos afirmar que o PAE idealmente consiste em um exercício supervisionado levado a cabo por um pós-graduando que deseje se voltar para as questões da docência no Ensino Superior. Dada essa afirmação, é importante pontuar que, no decorrer desse exercício, os lugares ocupados pelos parceiros (o docente e seu estagiário) determinarão a possibilidade do advento dos pontos de virada necessários para suscitar o surgimento de um novo professor universitário.

\section{O conceito de identificação}

Para refletir sobre a formação do professor universitário como um processo durante o qual é essencial que ocorram pontos de virada que permitam àquele que está em formação construir um trabalho que, na medida do possível, seja condizente com o seu estilo próprio, não se limitando a ser a reprodução dos processos que o formaram, o conceito de identificação nos é fundamental.

0 conceito de identificação substitui a noção de identidade que, via de regra, é compreendida como algo estável, e dá ao sujeito a falsa ilusão de ter construído um si próprio completo e independente do outro. Assim sendo, levar em conta a noção de identificação traz a vantagem de dar a ver que, ao contrário do que parece à primeira vista, a identidade é uma faceta do sujeito que pode mudar a cada instante.

\section{A identificação em Freud}

Freud escreveu sobre a identificação ao longo de toda sua obra (em especial, 1895; 1905; 1908; 1921; e 1924). Por esse motivo, trata-se de um conceito difícil de ser apreendido sem uma tentativa de percorrer de novo seu percurso de elaboração para refiná-lo paulatinamente. 0 psicanalista inicia sua exploração, em 1895, ao destacar de um caso clínico (o de Elizabeth Von R) uma especial aptidão dos neuróticos de tomar o lugar do outro e, por assim dizer, se doer com seus sofrimentos.

Dez anos mais tarde, o incansável pesquisador trabalhou sobre a formação de uma identidade de si mesmo, que o sujeito cria melhor ou pior de acordo com a modalidade de relação com sua mãe. Nesse primeiro momento, descrito por ele como uma espécie de estado maníaco, o sujeito aproveita-se dos cuidados que os adultos the dedicam para gradativamente construir uma atividade de representação por meio da qual vai poder construir uma imagem do corpo que, tendo um dentro e um fora e sendo dotado de orifícios, permite ao seu dono se aprimorar no processo de introjeção a partir do qual vai se constituindo como sujeito humano falante (Freud, 1905).

Em 1908, o interesse do psicanalista ainda estava voltado para a construção progressiva da imagem do corpo que é feita pelo sujeito. Destaca-se nesse momento a tentativa de circunscrever as funções do corpo (em especial as ligadas à reprodução da espécie) para poder habitá-lo de modo sexuado. É nesse momento que o sujeito pode polarizar as posições de homem e de mulher por meio dos atributos de ativo e de passivo, respectivamente.

6. Com relação a esse ponto, ressalte-se que uma especificidade do PAE na Faculdade de Educação é a existência da disciplina de pós-graduação EDM 5791 - Metodologia do Ensino Superior, cujos créditos são considerados como cumprimento da etapa de preparação pedagógica do estágio. 
Em 1921, Freud reconhece explicitamente que "a identificação é conhecida pela psicanálise como a mais remota expressão de um laço emocional com outra pessoa" (p. 115). Ao explicar o tipo de laço ao qual se refere, Freud esclarece que, mesmo tendo como essência tomar alguém como sendo seu ideal, trata-se de um processo ambivalente desde o seu início, podendo tornar-se expressão de ternura ou de hostilidade. Como se pode ver pelo parágrafo que se segue, nesse momento, Freud ainda flutua entre o campo dos investimentos objetais e o registro das identificações:

[...] primeiro, a identificação constitui a forma original de laço emocional com um objeto; segundo, de maneira regressiva, ela se torna sucedâneo para uma vinculação de objeto libidinal, por assim dizer, por meio de introjeção do objeto no ego; e, terceiro, pode surgir com qualquer nova percepção de uma qualidade comum partilhada com alguma outra pessoa que não é objeto de instinto sexual. Quanto mais importante essa qualidade comum é, mais bem-sucedida pode tornar-se essa identificação parcial, podendo representar assim o início de um novo laço. (p. 117)

Sua conclusão sobre esse conceito é elaborada no texto de 1924 . Freud afirma que na saída do complexo de Édipo ${ }^{7}$ cessa a confusão entre o investimento e a identificação, por meio de sua substituição por um processo identificatório, em que a criança deixa de ser sedutora com seus pais para identificar-se com uma incógnita: um $x$ que é o lugar singular que ela virá a construir no futuro, isso se abandonar as esperanças de tomar o lugar de um outro alguém.

A instalação de um processo identificatório, portanto, é aquilo que nos abre a rica possibilidade de nos reinventarmos a nós mesmos todas as vezes que nosso estado atual já não nos satisfaz. Ou dizendo de outro modo: por meio do jogo móvel das identificações, um sujeito está em permanente construção de si e de seu trabalho, num processo que pode ser de interminável inovação.

\section{A identificação em Lacan}

Optar por um lugar de fala singular de onde se possa delinear sua obra investigativa e de docência, por sua vez, força aquele que se autoriza a se tornar um professor universitário a estar em permanente contato com a dimensão criativa na condução de sua docência. Se, por definição, o singular é aquilo que não se repete, não é mais possível permanecer na cômoda posição de tentar copiar um modelo. Ao contrário, é necessário ousar inventar, por assim dizer, o seu próprio personagem.

lsto é, na perspectiva delineada até o presente ponto de nossa reflexão, tornar-se professor universitário não se relaciona com a adequação daquele que está em formação a modelos previamente construídos, mas, muito pelo contrário, refere-se à construção de sua capacidade de gerar um lugar de fala único.

Essa perspectiva pode ser mais bem elucidada por meio da recuperação de uma das principais teses desenvolvidas por Lacan no Seminário A identificação (1961-1962), qual seja: a impossibilidade absoluta de qualquer relação de identidade quando os significantes estão em jogo ${ }^{8}$.

Dito de outro modo, Lacan afirma que, como somos seres falantes - e, portanto, de certo modo submetidos à linguagem e suas leis -, não temos qualquer possibilidade de construir uma identidade fixa que se mantenha imutável ao longo de uma vida. A inadequação entre as qualidades predicativas com as quais um sujeito pode ser representado para os outros e o fundamento do ser é, segundo esse modo de ver, algo intransponível, a pedra no sapato que nos leva a uma dúvida eterna: quem sou eu?

\footnotetext{
7. Trata-se do momento no qual a criança abandona suas esperanças de obter um filho do genitor por quem está fantasmaticamente apaixonada. Ela abandona esse investimento, dessexualizando-o e sublimando-0.

8. Para sustentar essa idéia, o psicanalista partiu de um estudo de Heidegger no qual o filósofo estabeleceu uma diferença entre identidade e igualdade. Visando mostrar seu ponto de discordância com o filósofo, Lacan lançou mão de um importante exemplo: a frase "Meu avô é meu avô". Em sua análise, apesar de esse enunciado expressar uma igualdade, não expressa o princípio de identidade, uma vez que o primeiro meu avô se confunde com seu nome próprio, e o segundo é uma referência às estruturas de parentesco.
} 
Podemos perceber, acompanhando o raciocínio, que o sujeito tem uma dura escolha a fazer: ou bem ele assume que é um ser vivo e, portanto, deve se reinventar a cada instante ou bem se congela em uma mortífera identidade. A dimensão da criação se coloca novamente pela inexistência de resposta pronta para a pergunta a respeito da identidade do ser.

Caso existisse resposta preconcebida, bastaria para cada qual encontrar os atributos que melhor the definiriam e permanecer aderido a eles. Entretanto, como responder a essa pergunta é colocar o sujeito em terreno pantanoso (já que nenhum de nós tem certeza a respeito de quais palavras nos definiriam por uma vida toda), ele é obrigado a ir se agarrando a respostas provisórias: as identificações.

Ao retomar o trabalho de Freud (1921), Lacan descreve três tipos de identificação, a saber:

- Identificação à imagem proposta pelo outro: trata-se da identificação por meio da qual um sujeito pode vir a se compreender como sendo um eu, separado do outro do qual é, naquele instante da sua vida, objetivamente dependente. Ela permite a posterior construção de um dizer na primeira pessoa do singular como, por exemplo, "O bebê quer água", que pode vir a ser substituído por "Eu quero água”. Assim sendo, essa primeira identificação instaura o campo que possibilita o desejo: o da metáfora. Dizendo de outro modo, ao proporcionar uma primeira separação do sujeito do outro, esse nível de separação torna um querer subjetivado possível;

- Identificação ao significante puro: trata-se da identificação por meio da qual um sujeito toma emprestado (copia) um traço importante (o traço unário) de um personagem cuja relação foi sexualizada na fantasia da criança durante o período compreendido como Complexo de Édipo. É importante notar que, nesse caso, não se trata da cópia de uma imagem totalizante, mas sim do empréstimo de um significante que, na visão do sujeito, melhor caracteriza o objeto copiado como, por exemplo, tornar-se alegre como sua mãe, tornar-se rabujento como seu pai etc. Como essa identificação instaura um traço que passará a ser uma marca do sujeito, responde pela seguinte condição necessária para o exercício do desejo: "de onde desejar?"; e

- Identificação ao desejo inconsciente: trata-se da identificação estruturante por meio da qual um sujeito toma alguém, que para ele é percebido como um sujeito desejante, como modelo. A condição de alguém vir a ocupar o lugar de um objeto copiado, portanto, é dar mostras de estar em permanente busca de algo que poderia vir a suprir a insatisfação do seu desejo. Lacan confere a essa identificação o poder de reintroduzir, como falta, o objeto perdido, responsável pela insatisfação. 0 buraco daí advindo inaugura 0 inexorável movimento do desejo. Responde pela seguinte condição necessária para o exercício do desejo: "o que desejar?"

Estamos aqui defendendo a hipótese segundo a qual, na formação de um novo professor universitário, o processo identificatório é mobilizado e, idealmente, leva aquele que está em formação a construir um lugar próprio. Tal construção, por sua vez, só se edifica caso esteja apoiada no andaime composto pelas múltiplas identificações colocadas em jogo ao longo de seu percurso.

Dizendo de outro modo, é preciso que, para além do inevitável processo identificatório, haja lugar para o advento do desejo inconsciente naquele que está em formação. Para podermos discorrer sobre as condições de seu surgimento, recorremos a um excerto da obra de Lacan no qual o autor trata sobre a relação entre o desejo do sujeito e sua relação com o Outro.

Le désir ainsi se constitue d'abord, de sa nature, comme ce qui est caché à l'Autre par structure. Cèst l'impossible à l'Autre justement qui devient le désir du sujet. Le désir se constitue comme la partie de la 
demande qui est cachée à l'Autre. Cet Autre qui ne garantit rien, justement en tant qu'Autre, em tant que lieu de la parole, c'est là qu'il prend son incidence édifiante, il devient le voile, la couverture, le principe d'occultation de la place même du désir, et c'est là que l'objet va se mettre à couvert ${ }^{9}$. (Lacan, 1961-1962, p. 200)

Mesmo não sendo o caso de nos alongarmos aqui sobre o complexo conceito de desejo inconsciente, é necessário afirmar que, como se pode depreender do excerto citado, seu advento está em análoga correlação com a posição que ocupa o personagem com quem o sujeito se identifica.

Se, por acaso, ele concorda com a manutenção do processo identificatório e mantém-se na posição de ser aquele que deve ser copiado, a tendência é que o processo se perpetue. Ao contrário, se, por meio de uma deliberada opacidade e reticência com relação ao seu desejo (ou mesmo acidentalmente), ele dificulta a tentativa do sujeito de tornar-se a cópia fiel daquilo que lhe agradaria, é possível que um outro tipo de relação, mais marcada por uma parceria de trabalho, possa se instalar. Ao que parece, é essa segunda alternativa que mais se aproxima da experiência aqui analisada.

\section{Os pontos de virada}

0 caso que fundou o presente trabalho consiste no desenrolar do estágio PAE realizado por uma aluna do mestrado do programa de pós-graduação em Educação da FEUSP nas disciplinas EDM 0449 - Metodologia do Ensino de Lingüística l e EDM 0450 - Metodologia do Ensino de Lingüística 11. Trata-se de disciplinas cujos alunos são prioritariamente oriundos da graduação em lingüística da Faculdade de Filosofia, Letras e Ciências Humanas da USP, que têm a carga horária de 120 horas cada uma $(60 \mathrm{em}$ sala de aula e 60 de estágio supervisionado).

De modo muito abrangente, o objetivo das duas disciplinas é refletir sobre o uso da lin- guagem na dinâmica educativa nos variados graus de ensino. A partir dessa reflexão, pretendem propor diferentes abordagens metodológicas para o ensino da Língua Portuguesa; refletir sobre os pontos de contato entre a ciência lingüística e o ensino de Língua Portuguesa; e por último, iniciar a formação do aluno que, mais tarde, planeja tornar-se professor universitário de lingüística.

As turmas habitualmente têm cerca de 50 alunos. Como os graduandos em lingüística costumam ser pouco numerosos na USP, decidiu-se por ofertar também algumas vagas aos alunos do curso de Pedagogia, que podem cursá-la como disciplina optativa. Recebemos, ainda, professores de Língua Portuguesa da rede pública de ensino, esses últimos em regime de alunos especiais a quem são destinadas cinco vagas.

Descrito o programa, ater-no-emos ao caso estudado em sua singularidade. Para tanto, apresentaremos a experiência vivida pela estagiária e pela professora, salientando os fatos que compreendemos como pontos de virada na formação do professor universitário.

\section{Certezas desavisadas}

Para melhor situar a experiência analisada, é importante esclarecer que a aluna e a docente se conheceram quando a primeira estava cumprindo os créditos disciplina EDM 5062 - Escrita, subjetividade e ensino da pósgraduação - cuja ementa é a que se segue: A centralidade da linguagem para o humano. Conceito de sujeito para a psicanálise. Natureza e características do trabalho da escrita. Manifestações da subjetividade na escrita. 0 percurso do sujeito que aprende a escrever textos. 0 processo depreendido de rascunhos e versões de um dado texto. 0 papel dos mate-

9. "Deste modo, o desejo constitui-se inicialmente, por sua própria natureza, como o que está escondido no Outro pela estrutura. 0 impossível do Outro é justamente o que se torna o desejo do sujeito. 0 desejo se constitui como a parte da demanda que está escondida no Outro. Nesse Outro que, sendo o lugar da palavra, não garante nada. É lá que ele toma sua incidência construtiva, ele se torna o véu, a cobertura, o princípio de ocultação do lugar do desejo e é lá que o seu objeto vai se ocultar." (A tradução é nossa) 
riais que são utilizados como subsídio para a escrita (anotações, esquemas, esboços, textos lidos, aulas assistidas etc.). Dificuldades e inibições para escrever um texto que deverá ser sustentado em nome próprio. Especificidades e percalços do ensinar a escrever. OBJETIVOS: 1) Descrever o processo que se pode depreender mediante a análise de rascunhos e de material de base por meio dos quais um texto se constrói; 2) Examinar as marcas que permitem supor a manifestação de um sujeito singular na escrita; 3) Investigar sistematicamente as condições necessárias para o exercício da escrita que possa testemunhar uma criação, compreendida como a possibilidade experimentada por um sujeito de trabalhar para agenciar algo de novo (tendo como parâmetro sua própria experiência); e 4) Refletir sobre a pesquisa realizada pelo professor (de qualquer nível de ensino) que se dedica, em algum momento de sua formação, a investigar sistematicamente sobre quaisquer assuntos ligados ao seu exercício profissional.

De maneira especial, é crucial salientar que, ao realizar a matrícula, a aluna não conhecia a professora, o que proporcionou um terreno fértil para a mobilização de um imaginário que, mais tarde, revelou-se muito ligado ao tipo de identificação aqui descrito como incorporação.

Um ano mais tarde, em meio a boas gargalhadas, a aluna contou o seu lado da história para a professora, qual seja: ao tomar conhecimento do material informativo sobre a disciplina disponível no site da USP (ementa, objetivos, programa, bibliografia etc.) - antes mesmo de buscar qualquer tipo de informação sobre a docente responsável por sua criação -, ela imaginou tratar-se de uma senhora bastante idosa.

Ressalte-se que essa primeira imagem equivocada formou-se a partir de um julgamento da aluna a respeito da complexidade da disciplina. Em sua avaliação, só uma pessoa muito experiente poderia se autorizar a abordar os temas e textos psicanalíticos que foram propostos no curso em questão. Podemos concluir, então, que nesse primeiro contato entre a aluna e a docente, aquela mobilizou um modelo ideal de professor universitário: o de pessoa idosa, alguém vivido em número de anos.

É importante frisar nesse momento que, ao desconsiderar que não existe necessariamente equivalência entre o tempo de uma vida e a capacidade de elaboração de um sujeito, o modelo de professor ideal mobilizado pela aluna nesse primeiro momento consistia na atualização de uma tendência paralisante e improdutiva. De fato, pudemos perceber que um dos entraves para o progresso da aluna (que, na ocasião, estudava com seriedade a psicanálise há mais de quatro anos, mas jamais havia se manifestado publicamente sobre isso) era sua fantasia inicial: a de que é necessário ser uma mulher idosa para falar de psicanálise. Considerando a formação da nova geração de professores universitários, é de se interrogar, dado esse fato extravagante, quantas pessoas estão passivamente esperando o tempo passar para se autorizar a produzir... Felizmente, existem os tombos. Vamos a eles.

\section{Caindo do cavalinho... e identificando-se a alguns significantes}

0 primeiro tombo que a aluna levou foi o contato visual com a professora no primeiro dia de aula. Pela aparência, pôde perceber que a professora era muito mais jovem do que ela aluna poderia supor. Ainda aderida à sua fantasia da velha professora experiente, seu primeiro movimento foi o de recuo, pois, para não abandonar esse preconceito teria sido necessário encontrar uma jovem professora que ministrasse um curso inferior às expectativas da aluna. Felizmente, para além da imagem que nos cativa, há as palavras. Nesse caso, tão logo a professora começou a falar, a aluna mudou seu julgamento inicial. Em seu modo de ver, se não tinha encontrado uma professora senhora, ao que tudo indicava, estava na presença de uma senhora professora.

Nesse primeiro momento, já podemos perceber uma passagem no que tange à iden- 
tificação. Se, devida à contra-expectativa que a imagem corporal que a professora causava não foi possível fazer uma assimilação de sua pessoa com a personagem da fantasia da mulher idosa, a idade aproximada (e, por incrivel que pareça, até uma semelhança física entre docente e estagiária) permitiram uma incorporação (primeiro nível da identificação): eu sou como ela é.

Ter percebido a semelhança, nesse caso, foi muito benéfico, uma vez que proporcionou possibilidade para a instalação do segundo nível de identificação, àquela que advém em relação a alguns significantes. Mais especificamente, a aluna encantou-se não com a professora em si, mas com três traços bastante definidores de seu estilo de atuação durante a aula: a leveza, a inteligibilidade e a cordialidade.

Não se tratava mais de "eu e ela somos iguais", mas de uma espécie de "no dia em que me tornar professora universitária, quero ser como ela”, uma vez que os três significantes destacados serviram para alavancar um processo identificatório produtivo e cheio de desdobramentos. Foi nesse contexto que surgiu a vontade de solicitar uma orientação no programa PAE, considerado, inicialmente, como uma oportunidade para aprender a fazer igual. Foi, portanto, na busca de aprender a fazer como o outro faz que o estágio iniciou.

\section{A construção (cega) de um percurso singular}

0 estágio PAE começou bem antes do início das aulas. A docente indicou algumas leituras para que a estagiária já começasse preparada e, além disso, a incluiu na seleção e organização do material que seria utilizado e no planejamento da disciplina. Nessa fase, as parceiras definiram que as funções da estagiária seriam participar de todas as aulas, fazer três horas de monitoria semanalmente, coordenar seminários em grupo e orientar os alunos na elaboração de seu trabalho final. Além disso, algumas vezes, elaboraria e prepararia material para ser utilizado em sala.

A partir do trabalho propriamente dito, abriu-se espaço para a instauração do terceiro nível de identificação, pois, a partir de um contato mais estreito, a estagiária percebeu que formar pessoas era uma ação na qual a docente estava profundamente implicada. Demonstrava um interesse genuíno na formação da aluna e na criação de um espaço de docência no qual os alunos tinham grande importância.

0 início das aulas foi marcado, portanto, por uma grande curiosidade. A estagiária assistia às aulas com avidez de apreender sua estrutura e estratégias adotadas. Anotava cada comentário, cada atividade. Arquivou cuidadosamente todos os materiais produzidos para a utilização durante as aulas.

A relação da estagiária com os alunos foi muito amistosa. Sua participação começou tímida, mas, no final do semestre, já era freqüente e realizada sem apreensão. Foi bastante procurada pelos alunos que buscavam seu auxílio para discutir pontos de dúvida, bem como ajuda em relação aos seus seminários e trabalhos. Curiosamente, quem pôde notar isso foi a docente que a supervisionava. Esmerando-se em aprender a ser professora com a professora, ela julgava ocupar exclusivamente a posição de mais uma de suas alunas e não podia, ao menos inicialmente, darse conta do trabalho que vinha realizando.

\section{A invenção de um lugar para protótipo de novo docente...}

0 estágio PAE foi renovado no segundo semestre. Embora a maioria dos alunos tivesse cursado a disciplina no primeiro semestre, seu número cresceu. Como a professora solicitou à estagiária que se encarregasse de criar dispositivos para acolher os recém-chegados e informá-los dos tópicos mais importantes tratados ao longo do primeiro semestre, seu olhar mudou de foco. Responsabilizar-se pela inclusão dos novos interessados exigia deixar de mirar-se só na docente e, por assim dizer, examinar os novos alunos.

Esse momento consistiu em um ponto de virada muito importante que acarretou a percepção, por parte da estagiária, da complexidade da posição de um estagiário PAE. Se, por 
um lado, ele não é aluno da disciplina, muito menos uma espécie de secretário de luxo do docente, ele não é o professor da turma. Trata-se de inventar um lugar novo.

Dando-se conta dessa necessidade, a estagiária solicitou a oportunidade de ministrar uma das aulas da disciplina, mais especificamente, de ocupar duas das quatro horas que duravam cada encontro, solicitação esta que foi prontamente acatada. Durante a apresentação - que versava sobre um tópico da pesquisa da mestranda de interesse geral da turma -, a estagiária que, naquele momento, ocupava pela primeira vez o lugar de docente, ficou atenta às variáveis que, ao seu ver, conforme já mencionado, eram as marcas da atuação da professora responsável pela turma: a leve$z a$, a inteligibilidade e a cordialidade.

Apoiada nesses três significantes, Claudinha (modo carinhoso pelo qual vários alunos a chamavam para diferenciar da professora) ensaiou sua primeira aula. Esta, se não foi impecável no que tange à precisão conceitual, consistiu em um importante espaço de ensaio, inclusive, muito bem acolhido pelos alunos que encorajaram a estagiária e deram-lhe as mais variadas mostras de que, para eles, era possível compreender o fato de que, em uma primeira tentativa, não existe qualquer chance de sucesso absoluto.

Ressalte-se que a docente permaneceu atenta e atuante no decorrer da apresentação, amparando e, quando necessário, redirecionando a fala da estagiária, que foi alvo de discussão da turma ao fim da apresentação, consistindo, portanto, em um acontecimento importante para quem está interessado na discussão sobre metodologia de ensino. Reservadamente, foram discutidos aspectos mais pontuais da apresentação, em especial, aqueles que poderiam ser alvo de reparos posteriores.

O sonho da bússola: a transliteração do desejo inconsciente

Em sua tese de doutoramento, Riolfi (1999) realiza uma primeira aproximação entre o conceito de transliteração, desenvolvido por Allouch (1995) e a instauração da dimensão da singularidade na formação de professores. Segundo o autor, a transliteração consiste em uma nova dimensão da leitura que foi introduzida pela psicanálise quando esta afirmou que há o que se ler naquilo que se ouve, bastando o leitor conseguir desprender-se da dimensão da comunicação e efetuar uma construção analítica. Allouch ressalta que não se trata de ler entre as linhas, como quer a boca ingênua, mas, muito pelo contrário, de ler as linhas.

É importante frisar que para o autor tal possibilidade de leitura se coloca pela própria ação do inconsciente, compreendido como uma máquina de interpretar os eventos que escapam à compreensão consciente de alguém. Para o autor, o sonho cifra, pois "escrevendo, o sonho lê e, em primeiro lugar, lê o que na véspera não pôde ser ligado, em outras palavras, lido, e lido com um escrito" (Allouch, 1995, p. 70). Ou seja: para quem sabe ler, a função do sonho é a de revelar uma outra cena, na qual se inscreve uma verdade que não pode ser reconhecida pelo sujeito de outro modo.

Considerando o que foi apontado por Allouch, vale a pena recuperar aqui que, logo após sua conversa com a docente para avaliar sua primeira aula, a estagiária PAE teve um sonho, que transcrevemos, logo abaixo, tentando ser fiéis à primeira versão de sua narrativa:

Sonhei que estava escrevendo um artigo acadêmico com a professora Claudia Riolfi. Quando eu fui digitar os nomes dos autores, escrevi certo o meu próprio nome. Porém, sem me dar conta, quando fui digitar o nome da professora, eu o substituí pela palavra bússola.

Se aceitarmos a tese de Allouch (1995), segundo a qual o sonho escreve uma leitura já realizada pelo inconsciente do sujeito com relação a um evento vivido, poderemos afirmar que o sonho da bússola mostra, claramente, a instauração do último nível da identificação: a 
identificação a um desejo e não a uma pessoa ou a alguns de seus traços.

No final de um ano de trabalho, não se tratava mais de parecer-se com a docente nem de imitar o seu estilo de atuação, mas finalmente de aproveitar-se do seu percurso para constituir um norte, um modo de não se perder ao longo do caminho. Saliente-se que ocupar o lugar de bússola é radicalmente diferente de apresentar-se como mapa. Com um mapa, o sujeito trilha o mesmo caminho e chega ao mesmo destino. A função da bússola, nesse sentido, é oposta à do mapa, pois significa permitir a utilização de alguns parâmetros para trilhar, com mais segurança, o caminho singular que um sujeito escolheu.

A bússola é, para nós, a metáfora dos dispositivos que nos proporcionam a preciosa chance de nos reinventarmos como sujeitos. Dessa maneira, após ter ganhado a sua bússola como uma espécie de certificado de conclusão do estágio PAE, a aluna abdicou de considerar a imagem idealizada da professora como algo a ser replicado e autorizou-se a começar a falar de psicanálise antes de se tornar uma velha senhora. Aliás, diga-se de passagem que um dos frutos mais importantes dessa autorização é a própria elaboração do presente artigo.

\section{Considerações finais}

A mola propulsora para a elaboração deste trabalho foi perceber que as experiências vividas por professores e estagiários do PAE podem ser tomadas como um terreno fértil para a reflexão sobre a dimensão da singularidade na formação do professor universitário. Em especial, defendemos que se analisadas sob a perspectiva da psicanálise de orientação lacaniana, as vivências, no âmbito da formação de professores, podem ser instrutivas no que tange a uma militância ética contra uma universidade que se limite à reprodução.

Nossa reflexão nos permitiu concluir que a instauração de um estilo próprio de atuação para a geração de docentes que se forma só poderá ser sustentada se, nas duas partes envolvidas, existir disposição para o enfrentamento do que estamos chamando de pontos de virada, necessários para a superação do lugar genérico de aluno.

Não se trata de uma empreitada fácil. A principal dificuldade, ao nosso ver, a ser enfrentada pelos dois parceiros é a necessidade de abrir mão de parcela de seu narcisismo. Tal desprendimento é imposto pela própria constituição do mecanismo por meio do qual advém tudo o que é singular. Preso a um narcisismo imutável, o sujeito não consegue abrir mão do que pensa ser sua identidade e, conseqüentemente, em sua produção, atém-se a confeccionar tediosas variações sobre o mesmo tema.

Para o docente, é necessário um grande desprendimento para conseguir abrir um espaço genuíno desde onde o estagiário possa inventar e ocupar (ao menos parcialmente) uma posição de docente para os alunos da turma na qual realiza seu estágio. Quando preso em seu próprio modus operandi, o docente tende a valorizar as produções do estagiário que sejam efetuadas do modo que ele próprio teria feito, tendência esta que, evidentemente, diminui sobremaneira as chances do advento de inovações na condução pedagógica.

Em relação ao estagiário, o ato de abrir mão de parcela de seu narcisismo é necessário para superar o amedrontamento que a percepção de sua inexperiência e insuficiência gera. Só aqueles que são corajosos o suficiente para assumirem o risco de expor em público sua parcela de ridículo podem mostrar-se ao ponto de aceitar o desafio de falar a uma turma na presença e sob a supervisão de um professor considerado modelo.

A principal contribuição do presente trabalho, portanto, foi a de mostrar que, na formação do novo professor universitário, é necessário que ocorram sucessivos pontos de virada por meio dos quais o sujeito em formação venha paulatinamente abandonar o lugar daquele aluno que espera se tornar idêntico ao seu mestre, em benefício da incorporação de algumas de suas características que podem servir de suporte para construir outra coisa. 
Levando em conta o conceito de identificação, pudemos mostrar que, para percorrer o percurso necessário, é preciso passar por um esvaziamento inicial do imaginário de professor universitário ideal. Por sua vez, este abre lugar para um interesse na construção dos modos de fazer que podem dar corpo ao desejo de ensinar, que já se anunciava por ocasião da demanda de realização do estágio.

Para terminar esta reflexão, gostaríamos de retomar a epígrafe com a qual iniciamos o presente trabalho. Lacan (1975-1976) afirma que só se responsabiliza por seu fazer aquele que sabe fazer, ou seja, pode construir um estilo singular de conduzir a sua prática.

Transpondo essa afirmação para o contexto específico da formação de professores, podemos dizer que se responsabilizar pela própria prática implica em poder se autorizar a julgar a qualidade de seu fazer pelos resultados que obtém de seus alunos e não pela sua semelhança com o ideal ao qual se identificou para iniciar a construção de seu trajeto.

Dizendo de outro modo, estamos afirmando que o melhor resultado a ser obtido pelos programas do tipo PAE é levar o estagiário a valorizar o percurso que pôde construir ao longo do estágio, de modo a superar a frustração gerada pela constatação que, por mais que se esforce, não vai nem se tornar igual ao modelo que copia e, muito menos, ocupar o lugar do docente que o acolheu.

Encontrar modos para transformar os afetos advindos dessa perda em energia motivadora para a construção de sua obra (tornar-se professor ao seu próprio modo) parece-nos, portanto, consistir a grande questão que idealmente deve restar para quem concluiu seu estágio de formação docente. À universidade, caberia, portanto, a função de dar suporte aos ex-estagiários que se encontram nesse ponto de elaboração e recolher o saber depreendido de suas experiências, pois, ao que tudo indica, podemos aprender muito com isso.

\section{Referências bibliográficas}

ALLOUCH, J. Letra a letra: Transcrever, traduzir, transliterar. Rio de Janeiro: Campo Matêmico, 1995.

FREUD, S. (1895). Estudos sobre a Histeria (Breuer e Freud). Edição Standard Brasileira das Obras Completas de Sigmund Freud, v. II, 1974.

(1905). Três ensaios sobre a teoria da sexualidade. Edição Standard Brasileira das Obras Completas de Sigmund Freud, v. VII, 1974. 1974.

(1908). Sobre as teorias sexuais das crianças. Edição Standard Brasileira das Obras Completas de Sigmund Freud. v. XI

(1921). Psicologia das massas e análise do eu. Edição Standard Brasileira das Obras Completas de Sigmund Freud. V. XVIII, 1974. 1974.

(1924). A dissolução do complexo de Édipo. Edição Standard Brasileira das Obras Completas de Sigmund Freud. v. XIX

LACAN, J. (1961-1962) Le séminaire de Jacques Lacan. Livre IX: L'identification. Publication hors commerce Document interne à l'Association freudienne internetionale et destiné à sés membres, 1998.

(1975-1976) Le séminaire de Jacques Lacan. Livre XXIII: Le sinthome. Paris: Éditions du Seuil, 2005.

PIMENTA, S. G.; ANASTASIOU, L. G. Preparação pedagógica: uma experiência em discussão. PAE: Programa de Aperfeiçoamento de Ensino. Universidade de São Paulo. Pró-Reitoria de Pós-Graduação, São Paulo, 2001. 
RIOLFI, C. R. 0 discurso que sustenta a prática pedagógica: formação de professor de língua materna. 1999. Tese (Doutorado). Instituto de Estudos da Linguagem. Universidade Estadual de Campinas, Campinas, 1999.

Formacriação. Revista Línguas e Letras, Unioeste. v. 2, n. 1, 1º. Semestre de 2001, p. 13-18.

0 amor à diferença no trabalho enlaçado no interior de grupos. Trabalhos em Lingüística Aplicada. Unicamp, Campinas, 39. Jan./jun. 2002. p. 37-45.

UNIVERSIDADE DE SÃO PAULO: Pró-Reitoria de Pós-Graduação. PAE: Programa de Aperfeiçoamento de Ensino. São Paulo, 2001. UNIVERSIDADE DE SÃO PAULO. Portaria GR 3588. Disponível em: <www.usp.br>. Acesso em: 20 de janeiro 2005.

Recebido em 17.03.06

Aprovado em 04.09.06

Claudia Rosa Riolfi é psicanalista, doutora em Lingüística, professora das disciplinas de Metodologia de Ensino de Língua Portuguesa, Lingüística e Alfabetização da Faculdade de Educação da Universidade de São Paulo.

Cláudia Alaminos é fonoaudióloga, psicopedagoga e mestre pela Faculdade de Educação da Universidade de São Paulo. E-mail: claudia.alaminos@ajato.com.br 